\title{
Epistemic injustice and deepened disagreement
}

\author{
T. J. Lagewaard ${ }^{1}$
}

\begin{abstract}
Sometimes ordinary disagreements become deep as a result of epistemic injustice. The paper explores a hitherto unnoticed connection between two phenomena that have received ample attention in recent social epistemology: deep disagreement and epistemic injustice. When (pre-existing) epistemic injustice comes into play in a regular disagreement, this can lead to higher-order disagreement about what counts as evidence concerning the original disagreement, which deepens the disagreement. After considering a common definition of deep disagreement, it is proposed that the depth of disagreements is best understood as a matter of degree. Then, a case study of real-life disagreement is introduced: the disagreement about whether racism is a significant issue in the Netherlands, illustrated by the tradition of 'Black Pete'. It is argued that there is disagreement about what counts as evidence in the case study because of two forms of epistemic injustice: testimonial and hermeneutical injustice. Specifically, there is disagreement about (the application of) epistemic principles concerning (A) whether private first-personal experience of racism is a weighty source of evidence in this domain, (B) whether victims of racism count as important testifiers in this domain, and (C) how to assess testimony that is not (fully) intelligible to you because it employs concepts and terminology you are unfamiliar with. By dismissing the relevant testimony and epistemic resources, the disagreement boils down to disagreement on the level of epistemic principles concerning (A), (B), and (C). Introducing injusticebased deep disagreement highlights moral and political aspects of disagreements that might seem factual.
\end{abstract}

Keywords Epistemic injustice - Deep disagreement - Testimonial injustice · Hermeneutical injustice $\cdot$ Racism $\cdot$ Epistemic principles

T. J. Lagewaard

t.j.lagewaard@vu.nl

1 Department of Philosophy, Vrije Universiteit Amsterdam, Amsterdam, The Netherlands 


\section{Introduction}

Disagreement is a fact of life. Some disagreements are merely temporary and easily resolved, while others become entrenched, systematic and can seem very difficult, if not outright impossible, to resolve. While social epistemologists have given a lot of attention to disagreements of the former kind-especially to the question of what is the rational response to ordinary disagreement (e.g., Kelly 2005; Feldman 2006; Christensen 2007) — much less has been written about the latter, more intractable, type of disagreements (e.g. Fogelin 1985; Memedi 2007; Lynch 2010; Kappel 2012).

My goal is to contribute to a better understanding of what has been called deep disagreement: disagreements that involve disagreement about underlying epistemic principles. Deep disagreements are not just a theoretical puzzle for social epistemologists. As Kappel (2012) and Lynch (2010) highlight, they can cause practical problems for collective decision making, because collective choices often depend on shared factual beliefs. This way, deep disagreements can hamper collective choices and policy making.

The main claim of this paper is that sometimes ordinary disagreements become deep as a result of epistemic injustice, i.e., injustice that occurs when someone is wronged specifically as an epistemic subject (Fricker 2013: 1320; 2017: 53). The paper thus explores a hitherto unnoticed connection between two phenomena that have received ample attention in recent social epistemology: (deep) disagreement and epistemic injustice.

The central idea is that when (pre-existing) epistemic injustice comes into play in a regular disagreement, this can lead to disagreement about what counts as evidence concerning the original disagreement. This disagreement on relatively fundamental epistemic principles makes the disagreement deep. Introducing injustice-based deep disagreement highlights moral and political aspects of disagreements that might seem factual.

The plan is as follows: in Sect. 2 I introduce and modify a common definition of deep disagreement and propose that the depth of disagreements is best understood as a matter of degree: disagreements can be more or less deep. Next, in Sect. 3, I introduce and explore a case study of real-life disagreement: the disagreement about whether racism is a significant issue in the Netherlands, illustrated by the case of 'Black Pete'. As the Netherlands is often seen as a liberal and tolerant place, where one might expect questions about racism to be addressed in a cool and evidencebased manner, focusing on the debate on racism in this country will be especially helpful to illustrate my points. In Sects. 4 and 5, I argue that there is disagreement about what counts as evidence in the case study because of two forms of epistemic injustice: testimonial and hermeneutical injustice. In Sect. 6, I discuss how these epistemic injustices deepen the initial disagreement about racism and conclude that the intersection of disagreement and epistemic injustice is a fruitful area for future work in social epistemology. 


\section{What are deep disagreements?}

The notion of deep disagreement does not have a firmly established meaning, but often involves a dependency of first order disagreement on higher order disagreement about evidence. This dependency can be described in different ways. ${ }^{1}$ In this section, I discuss a common way to characterize deep disagreement in social epistemology, raise a concern with it, and then provide a modified characterization.

Here is an example of a case that is often used as a paradigm of deep disagreement, for example by Ranalli (2018: 2):

[Young Earth Creationist] Henry and Richard disagree over the claim that Earth is no more than 6000 years old. Henry, a Young Earth Creationist, accepts this claim while Richard rejects it. Henry's evidence consists of conspiratorial claims about science misleading us about the age of the Earth, as well as a literal reading of the Bible. He considers the Bible a source of knowledge about the age of the Earth and rejects the theory of evolution and contemporary cosmology as reliable sources of knowledge on this topic. Richard, on the other hand, rejects the Bible as a source of knowledge about the age of the Earth and instead accepts the theory of evolution and contemporary cosmology as sources of knowledge about the age of the Earth.

What makes this kind of disagreement special? It is not just a disagreement about facts (the age of the earth) but also about the relevant methods, evidence, standards, and arguments to be used to obtain knowledge in the domain under discussion. Henry believes a literal reading of the Bible is the best source of evidence bearing on the age of the earth, while Richard believes inferences from fossil records, carbon dating, and other widely used scientific methods are the way to go. They disagree on quite basic epistemic principles; they are in deep disagreement.

Lynch (2010), Kappel (2018) and Matheson (2018) all define deep disagreement as disagreement about 'fundamental' or 'basic' epistemic principles. ${ }^{2}$ The example above, [Young Earth Creationist], is often used as an example of disagreement about fundamental epistemic principles.

An epistemic principle tells us how we should form our beliefs. Such a principle concerns what counts as reliable evidence for what and/or what counts as justified belief regarding a certain domain (Lynch 2010). For example, the epistemic principles of tasseography tell us that we can gain justified beliefs about our fortunes

\footnotetext{
1 Thanks to an anonymous reviews to pointing out this nuance.

2 Deep disagreement can also be defined differently, in a Wittgensteinian way, as involving conflicting hinge propositions (Ranalli 2018; Aikin 2018). Further, in this paper I focus on epistemic deep disagreements. I leave moral and metaphysical deep disagreement to the side (for more on these kind of disagreements, see Ranalli 2018), because I want to focus on the specific epistemological dimension of complex disagreements. In this paper, 'deep disagreement', means 'epistemic deep disagreement'. This does not mean that the disagreements I discuss cannot have morally relevant dimensions as well; it's just that my focus is on the epistemic principles involved in the disagreement.
} 
by interpreting the patterns of coffee grounds. We all accept certain epistemic principles when forming and updating beliefs.

One way to distinguish between different epistemic principles is by separating fundamental principles from derived epistemic principles. As Matheson (2018: 3) puts it: 'Fundamental epistemic principles are simply basic; they are not derived from any other principle.' An epistemic principle is fundamental when exchangeable epistemic reasons in favor of it presuppose some positive epistemic status, like reliability, of this same principle (Ranalli 2018, 10). Hence, the reliability of these principles can only be argued for in a circular way. What principles are fundamental in this sense? On a reductionist view, principles like visual perception, deduction or introspection are often considered to be fundamental. On a non-reductionist view, testimony is also a fundamental source of knowledge (Lackey 2008). What makes them fundamental is that, in the end, any arguments for the reliability of these principles will be circular (Fogelin 1985; Alston 1986; Feldman 2005).

This means deep disagreements cannot be resolved in a dispute-independent way. They are not resolvable by exchanging epistemic reasons that both parties accept as epistemic reasons within their respective sets of epistemic principles. There will be many epistemic reasons that are such that, were the disagreeing parties in [Young Earth Creationist] to offer them to the other party in an attempt to change their mind, the other party would simply fail to see it as a good or valid reason, because the reason isn't a good or valid one according to their set of epistemic principles.

We've seen that deep disagreement has been characterized as having to do with fundamental epistemic principles. But here is a concern for this definition: the paradigm example introduced above, [Young Earth Creationist], could be thought not to fit the 'fundamental epistemic principle' definition used by Lynch, Kappel and Matheson, even though they themselves use examples very similar to it.

The example does not fit the definition, because Henry and Richard do not disagree about fundamental epistemic principles but about derived principles. They disagree, among other things, about whether the Bible is an important source of knowledge about the age of the earth. The epistemic principle 'The Bible is a source of knowledge about the age of the earth', does not seem fundamental in the way principles concerning perception or introspection do. In the case of the Bible as source of knowledge, there are other, more fundamental, epistemic principles that can be invoked to argue for and against this principle, such as principles concerning divine revelation, testimony, or induction. Similarly, the epistemic principle that tells that we can gain knowledge from evolutionary science seems derived and not fundamental. Its reliability could be shown by pointing to the reliability of science or scientific methods in general, which in turn could be defended by pointing to the reliability of, for example, sense perception, which can only show to be reliable with circular arguments. The principle concerning evolutionary science it not itself fundamental. But this would mean that the paradigmatic example isn't really an example of deep disagreement after all. ${ }^{3}$

\footnotetext{
3 One could argue that the epistemic principles in [Young Earth Creationist] are, after all, fundamental, by using a more expansive reading of 'basic epistemic principles' to include some derived principles. My point, however, is that the work of Kappel, Lynch and Matheson does not permit a more expansive
} 
One response to this concern would be to look for different examples that fit the characterization better, or perhaps to rewrite the [Young Earth Creationist] example so as to fit the characterization. I would argue against this, however. Another approach to thinking about deep disagreement is to consider what kinds of disagreements you want a characterization to cover. It seems clear that [Young Earth Creationist] is as good an example as any of the kinds of real-life systematic, entrenched, deep disagreements one would want to include.

Disagreement about fundamental epistemic principles (in the sense described above) will be rare in real life, because apart from the textbook radical sceptic, few if any people disagree about, say, the reliability of perception. Disagreement about less fundamental principles, like the reliability of the methods of evolutionary biology, neuroscience, or social psychology will be more common. If we are interested in better understanding real-life cases of deep disagreements, as I think we should be, it is important to include a case like [Young Earth Creationist] in the set of deep disagreements. Therefore we should develop a characterization of deep disagreement that is true to what intuitively seem like good examples of real cases of deep disagreement.

A way to do this is to introduce gradation in the characterization of deep disagreement. Aikin $(2019,422)$ argues that 'depth' is a gradable notion: things can be more or less deep. Depth is also a comparative notion. Aikin writes that some things are deeper than others and concludes: 'not only are some disagreements deeper than others, some may be profoundly deep.' Duran $(2016,5)$ similarly argues that that we should not see 'deep disagreement' as absolute. Given that some historical real-life deep disagreements are resolved, he concludes that some disagreements are deeper than others. Dutilh Novaes et al. (2020), also use the notion of deep disagreement as being graded.

There may be different ways of cashing out the depth of disagreements. Here, I propose applying the term to disagreements about less fundamental epistemic principles as well. Disagreements about epistemic principles could be placed on a spectrum, ranging from disagreement regarding epistemic principles that are not fundamental at all to the deepest kind of disagreement. Disagreements about fundamental epistemic principles could be considered the 'deepest' kind of disagreement. A disagreement about whether to use Google Maps or the similar app from Apple as a source of evidence about the most efficient route could be placed on the other side of the spectrum, as it is a disagreement about derived epistemic principles. Moving up the spectrum, the higher-order disagreements will be about epistemic principles that are less derived. Not all higher-order disagreements are deep, but at some point on the spectrum disagreement will be about relatively fundamental epistemic principles. When is a principle 'relatively fundamental'? As said, fundamental principles are those that can only be shown to be reliable by circular argumentation. This can be extended to also involve principles that directly rely on such fundamental principles. These principles are, so to speak, only 'one

Footnote 3 continued

reading. Also, using a slightly different notion of 'basic epistemic principles' and introducing gradation in the notion of deep disagreement is not necessarily in contradiction with each other. 
step away' from circularity and can therefore be seen as relatively fundamental. I propose that the more 'steps' one needs to come to a principle that can only be defended in a circular way, the less fundamental the principle is. I further propose to call those principles that need just a few steps to run into circularity 'relatively fundamental principles' in order to flag that these are principles for which it will be very difficult to find epistemic reasons that are accepted by both parties. From that points onwards, it seems useful to call disagreements 'deep'. This way, disagreements about epistemic principles that are not quite as fundamental as perception or memory, could still be classified as 'deep' or as 'deeper', depending on where one draws the line.. Using such gradation, [Young Earth Creationist] and other interesting real-life disagreements like it can be considered deep(er) disagreements.

A deep disagreement, then, involves disagreement about relatively fundamental epistemic principles. This looser characterization of deep disagreement is the one I'll use in this paper. In the next section, I'll explore a case of real-life deep disagreement: the debate about racism in the Netherlands, in order to show how epistemic injustice can deepen disagreement.

\section{Racism}

In the Netherlands, there is disagreement about whether racism in Dutch society is a significant problem (Ghorashi 2014; Wekker 2016; Essed 2018). While this may look like an ordinary disagreement that could be resolved easily by attending to the relevant data and experiences, I will show that it is in fact a deep disagreement, because there is underlying disagreement about what counts as evidence for the claim that racism is a significant issue in the Netherlands. Although this disagreement has moral aspects as well, my focus is on its epistemic aspects.

There is not a single concept of racism. Different groups use (slightly) different concepts that overlap to different degrees. Many people describe racism as a complex system of prejudice and discrimination based on an ideology of racial domination and racial oppression (Essed 2018). In this paper I use the concept of 'everyday racism' (Essed 1991). Although extreme and overt forms of racism are easily recognized (and might not be as prevalent in Dutch society), everyday racism is harder to spot. Everyday racism can be more coded ('your Dutch is so good!'), ingrained in institutional practices, or not consciously intended. Everyday racism, according to Essed, is 'a process of smaller and bigger day-to-day violations of the civil rights of ethnic minorities - and of their humanity and their dignity' (Essed 2008: 447). Hence, everyday racism isn't so much about individual actions, which might all be relatively harmless and create only minor inequities, but about the accumulation of many such individual actions, the result of which is 'the marginalization of those identified as racially or ethnically different' (Idem: 448). What makes an action, situation, structure or event racist is that it contributes to this marginalization.

The disagreement on racism I am interested in here, then, is about whether everyday racism and the systemic inequalities it produces are a significant problem in Dutch society. Racism is a significant issue, I propose, when people of color are 
structurally at a disadvantage as a result of bigger or smaller inequities in various parts of their lives due to racial discrimination.

There is ample statistical evidence that in Dutch society racism is indeed a significant problem. For example, people with a 'foreign' sounding name have a lower chance to be invited for a job interview than equally qualified people with a Dutch sounding name, even if these latter people have a criminal record (Van den Berg et al. 2017). In addition, people of color have a harder time renting houses or apartments (Rasit and Tielbeke 2018). Highly educated Dutch with a non-western background are more often unemployed (Huijnk et al. 2014) and youth with a migration background are, compared to their peers without a migration background, suspected and convicted in higher numbers for the same kinds of offences. Furthermore, a big part of Dutch Surinamese, Antilleans, Turks and Moroccans (the four biggest minorities in the Netherlands) report experiencing racism regularly (Huijnk et al. 2014). All of this presents evidence for the claim that racism is indeed a problem in the Netherlands, as these examples show that people of color face systemic equities.

However, due to the coded and ingrained nature of everyday racism, it's hard to point to specific actions and establish 'objectively' that they are indeed clear cases of racism. This leaves room for disagreement. And indeed, there is plenty of disagreement about whether the above evidence establishes that racism is a significant problem. Many Dutch people tend to see themselves as tolerant and antiracist (Wekker 2016: 1). Hondius (2014: 273) characterizes a broadly shared sentiment in Dutch society when she writes: 'Racism is simply 'not done', also meaning to suggest literally that it does not happen; it is considered self-evident that variety in skin tone is unimportant, irrelevant, and meaningless.' She adds that this denial of racism has the consequence that there is not a lot of debate about it in public discourse.

Although racism in general isn't high on the agenda of public discourse in Dutch society, the issue of racism resurfaces indirectly in the heated debate on whether the figure of Black Pete is a racist stereotype. For many, this debate is not just about Black Pete. Rather, the Dutch attitude towards Black Pete epitomizes the lax attitude towards racial discrimination in general. In what follows I'll use this debate as my main illustration of how epistemic injustice can deepen disagreement, but let me introduce the debate first.

Who is Black Pete? The Netherlands cherishes its traditional family feast of St. Nicholas, an old and wise bishop. Each year, on the evening of December $5^{\text {th }}$, St. Nicholas visits children's homes to bring them gifts and candy. His helper in this daunting task is 'Black Pete', a blackened, obedient, cheerful, and sometimes silly figure. Black Pete has a wig of afro hair and his (or her) face is painted wholly black. Often, he wears large golden earrings, Renaissance clothing and he sports red-painted lips. Starting around October, images and dressed-up people representing St. Nicholas and Black Pete are widely present in parades, streets, stores, schools, and national and local television.

The appearance and role of Black Pete has been under discussion since the sixties. Until recently, however, none of this debate made it into mainstream media and national public discourse. This has changed sharply over the past decade and 
Black Pete is now the centerpiece of heated debate in Dutch society. The central bone of contention is whether the appearance of Black Pete is a racist stereotype and thus should be abolished. The UN has (unsuccessfully) called upon the Dutch government to "actively promote the elimination" of racial stereotyping. ${ }^{4}$ The debate also received some attention in the international press ${ }^{5}$ and has been discussed in scholarship (e.g., Hilhorst and Hermes 2016; Rodenberg and Wagenaar 2016).

Although numbers have shifted in recent years, a large majority of the Dutch $(80 \%)$ believes Black Pete is not a racist phenomenon. Two-thirds report not understanding that Black Pete can come across as (unintentionally) racist and the same proportion of people feel that there should not even be debate about the appearance of Black Pete (Van Vliet and Kester 2018). A minority, however, believes the character of Black Pete is perpetuating negative stereotypes of black people. A majority (73\%) of the black population feels discriminated against or hurt by the appearance of Black Pete (idem). Black Pete is perceived as a symbol of the blind spot Dutch people have for the occurrence of racism (Wekker 2016). Because of this, a growing minority of people wants the appearance of Black Pete altered to eliminate his stereotyped features or even have the figure abolished altogether.

One could doubt whether the dispute about Black Pete should be described as a disagreement as not everyone involved uses the same concept of racism. For example, some people who think that Black Pete should not be changed use a rather restricted concept of racism on which Black Pete is not obviously a racist tradition. On the other hand, people who think that Black Pete should be changed, sometimes use a more expansive concept, like 'every day racism' on which Black Pete is more obviously racist (Dutilh Novaes et al. 2020). In light of this, it could be thought that the disagreement about Black Pete (and racism) merely involves equivocation with respect to the word 'racism' and does not involve meaningful (deep) disagreement. ${ }^{6}$ After all, if there is indeed no shared object of disagreement, there is no meaningful disagreement.

However, I do think there is genuine disagreement to be found and hence, that this is not a case of simple equivocation. As I see it, two different kinds of disagreement can be distinguished concerning Black Pete. The first is a regular 'propositional' disagreement about whether Black Pete is a racist figure. Secondly, there is 'metalinguistic disagreement' about what concept of racism to use. Disagreement about which concept to use can be a case of genuine and substantive disagreement (Plunkett and Sundell 2013; Stroud 2019).

But, one could wonder, is there still a propositional disagreement if there is also a metalinguistic disagreement? I do think there is genuine propositional disagreement to be found here, despite of the meta-linguistic disagreement about the concept 'racism'. The disagreement centers on the following proposition: 'The Black Pete

\footnotetext{
4 See: https://www.nytimes.com/2015/08/29/world/europe/zwarte-piet-netherlands-united-nations.html.

5 For example in the New York Times: https://www.nytimes.com/2015/08/29/world/europe/zwarte-pietnetherlands-united-nations.html and in The Guardian: https://www.theguardian.com/world/2017/nov/28/ black-pete-extreme-right-appears-to-stoke-dutch-divisions.

6 Thanks to an anonymous reviewer for raising this point.
} 
tradition contributes to practices that serve to disadvantage certain non-white parts of the population in an unjust way'. People who use a narrow concept of racism may disbelieve this proposition and think that the tradition does not have these effects. This disbelief may be in part due to their use of a narrow concept of racism. On the other hand, people using a broader concept of racism may believe the proposition, partly because of their use of a broader concept. For most people 'disadvantaging certain parts of the non-white population in an unjust way' qualifies as racist, so they may describe Black Pete as racist, while people who disagree with the proposition might say that Black Pete is not racist. For the sake of brevity, in the remainder of this paper I use 'Black Pete is racist' as shorthand for the proposition 'The Black Pete tradition contributes to practices that serve to disadvantage certain non-white parts of the population in an unjust way'. Even people who do not share the same concept of racism can meaningfully disagree about this proposition.

Both propositional and meta-linguistic forms of disagreement concerning Black Pete merit attention and addressing both and how they interact will provide a more complete picture of the disagreement on racism. However, in this paper I focus on the propositional disagreement concerning racism and Black Pete.

So far, the debate on racism might look like an ordinary disagreement that could be rationally resolved by apprising people of the relevant evidence and testimonies pertaining to the occurrence of racism in Dutch society. However, the debate has become extremely polarized and entrenched and has led to political and even physical clashes. ${ }^{7}$ How did it get this far? I will now go on to argue that the disagreement about racism has deepened because it involves disagreement about what constitutes good evidence for the proposition that racism is a significant issue in the Netherlands. The main source of evidence that is contested are the testimonies of people who have first-hand experiences of racism. Because this source of evidence is contested, the disagreement about racism becomes deep. ${ }^{8}$ This deepening is caused by epistemic injustice, or so I will argue. The contesting of the testimony constitutes part of the racism that is debated. In Sect. 6, I will present my argument in more detail, but first, I turn to epistemic injustice.

\section{Testimonial injustice and deep disagreement}

Much has been written about epistemic injustice following Fricker's (2007) introduction of the term (Kidd et al. 2017 provides an excellent overview). ${ }^{9}$ Epistemic injustice occurs when someone is 'wronged in their capacity as an

\footnotetext{
7 For example, in November 2017 a group of pro-Black Pete activists blocked a highway to prevent antiBlack Pete protesters from traveling to the annual arrival of St. Nicholas in November, which is broadcast on national television every year (see the article in The Guardian referenced in note 3 above).

8 Or, alternatively, perhaps it was always deep and my analysis explicates why this is so.

9 Here and throughout, I use 'epistemic injustice' to stand for 'discriminatory epistemic injustice' as opposed to 'distributive epistemic injustice' as described by Coady (2017) and Lackey (2018). Also, I intentionally say 'introduction of the term' rather than 'concept', because-ironically-according to
} 
epistemic subject' Fricker 2017: 53). ${ }^{10}$ Fricker distinguishes two forms of epistemic injustice: testimonial and hermeneutical. Broadly speaking, testimonial injustice happens when a testifier's credibility is deflated because of identity prejudices in the receiver's judgement- negative stereotypes related to class, race, gender, or social power that track a person through several spheres of her life (Fricker 2007: 20-28). Hermeneutical injustice happens when, due to identity prejudices, 'a subject who is already hermeneutically marginalized (that is, they belong to a group which does not have access to equal participation in the generation of social meanings) is thereby put at an unfair disadvantage when it comes to making sense of a significant area of their social experience (Fricker 2013: 1319). There are several variants of hermeneutical injustice. One form that is particularly relevant to this paper occurs when a person is hindered in sharing conceptual resources which she herself possesses with people outside her group (Dotson 2012: 32; Fricker 2013: 1319; 2016: 166-167; Medina 2017: 43-44). In this section, I show how testimonial injustice can deepen disagreement. In the next, I'll do the same for hermeneutical injustice. The result is injustice-based deep disagreement: disagreement that is deep due to epistemic injustice. The disagreement about racism in the Netherlands will continue to serve as my main illustration throughout.

Testimonial injustice occurs when a testifier suffers a credibility deficit due to an identity prejudice on the part of the receiver (Fricker 2007: 28). Someone suffers from a credibility deficit when she is systematically wrongly judged by others to be less credible than the evidence says that she is. When someone gives testimony, for example, on the weather in Switzerland or the workings of a PET-scan, we make credibility judgements. We judge the credibility of both the content of the testimony and the testifier (Lackey 2008; McKinnon 2016: 437). The goal is to judge as credible only those testifiers who are actually credible, because this contributes to gaining justified beliefs and avoiding unjustified ones.

There is a host of factors that can and should be considered when judging whether a testifier is credible, like the track record of the testifier and your background information on the subject matter at hand (Fricker 1995: 404-405). For example, a receiver can consider whether the testifier spoke in a confident or nervous way (Goldberg 2015). There are also factors that easily affect credibility judgments in practice, but rationally should not do so. Among those are identityprejudices. These are not just any prejudices, but prejudices that track people in different spheres of their lives (for example their education, work, and relationships). This happens, for example, when a woman's testimony is not taken seriously because of a prejudice that women are overly emotional. In such a case, the testifier suffers a credibility deficit based on a stereotype that tracks women systematically.

Footnote 9 continued

McKinnon (2016), there is a history of black feminist thought on the concept of epistemic injustice before Fricker named and described this concept.

10 The term 'epistemic subject' is intentionally broader than 'knower', which Fricker (2007) originally used in her characterization of epistemic injustice. By replacing 'knower' with 'epistemic subject', not only a 'knower' can be the victim of epistemic injustice, but also a subject who lacks knowledge, but is, compared to others, better justified can be a victim of epistemic injustice (Gerken 2019). 
Another example is when someone attributes less credibility to a testifier with disabilities than is appropriate because of ableist prejudice. When judging a testifier's credibility based on identity-prejudices, a receiver of testimony runs the risk of assigning too little credibility, thereby creating a credibility deficit. This can result in testimonial injustice in the form of a lack of uptake of testimony.

Testimonial injustice is not only a problem for those who fall victim to it. The person not attributing (enough) credibility does not take into account all available evidence or does not give appropriate weight to a certain part of her evidence (to wit, the relevant testimony). As a result, her beliefs do not adequately reflect the available evidence (Fricker 2007: 43). This is particularly bad when someone dismisses the trustworthy testimony of someone who has in fact good evidence. In such a case, the discrepancy between evidence and judgment is even bigger.

I'll now go on to argue that the debate about racism in the Netherlands is plagued by testimonial injustice: the victims of racism aren't given enough credibility. Then, I show how this turns disagreement about racism into deep disagreement.

I start by arguing that people who experience racism often have important information when it comes to racism. First-personal experience of racism can give them good evidence concerning racism.

Sometimes, a non-dominant group can have an epistemic advantage over the dominant group when it comes to knowledge and understanding of oppression (Mills 2007; Dormandy 2018). This is because, as Berenstain (2016) and others note, someone who experiences a form of oppression, like racism, has one additional way of acquiring knowledge about oppression compared to others who don't suffer from it. Everyone can learn about oppression through testimony from those who are oppressed and through scientific evidence about it, but only the oppressed themselves can acquire knowledge about oppression through firstpersonal experience of it. The first-personal experience of a minority group member who experiences racism is an important source of evidence bearing on the disagreement about evidence.

These first-personal experiences are not only an important source of information, but also a distinct one. They can be a distinct source of evidence bearing on the disagreement about racism because of the social position of people who experience racism. As feminist epistemologists such as Harding (1993) and Pohlhaus (2012) have emphasized, your social position in the world shapes how you see the world. It shapes what you do and do not notice and what you pay attention to. Differences in experiences (due to differences in social position) can lead to differences in so called epistemic perspectives.

This difference in standpoints leads to an epistemic asymmetry between oppressed and non-oppressed people, whereby oppressed people have an epistemic advantage when it comes to the relevant oppression (Medina 2013, 197). This is because the perspective of oppressed people can give them a more accurate picture of the relevant part of the social world (Harding 1993). As your standpoint shapes what you notice and pay attention to, people who face a certain kind of oppression will, on a group level, pay more attention to this part of the social world. 'Paying more attention' to a certain part of the world does not necessarily lead to more 
knowledge or justified belief, but it can put an oppressed group in a better epistemic position.

Oppressed groups derive their epistemic advantage from 'having knowledge of the practices of both their own contexts and those of their oppressors', (Narayan 2004, 221). Medina (2013:197-198) argues that for very specific domains of knowledge, domains of oppression, people who are oppressed can have more knowledge than people who are not oppressed. People who are oppressed are often able to see the world both from the perspective of the oppressed and of the oppressor. This gives them more knowledge about the oppressors than the oppressors have about themselves. A member from the dominant group has no similar interest to learn about the situation of the dominated group. This causes an asymmetry in knowledge, which leaves the dominated group relatively advantaged (Narayan 2004).

This does not mean that someone who does not experience a certain kind of oppression cannot have knowledge about being in that situation. What it means is that it is 'easier and more likely for the oppressed to have critical insights into the conditions of their own oppression than it is for those who live outside these structures (Narayan 2004, 220)'. However, people who do not experience racism, due to their social position, may have a 'blind spot of racial insensitivity' (Medina 2016: 185). From their (dominant) point of view, there might be a lack of evidence for the significance of racism.

One could object that experiencing racism in a situation does not necessarily mean that there actually is racism in that situation. And one could object that a person who experiences racism does not automatically apply the concept of racism in the right way to new situations.

This is correct as far as it goes-nobody automatically applies any concept infallibly to anything. But we can note that the 'epistemic advantage' in question is a group perspective. As the number of people reporting similar first-personal experiences increases, the scenario that all of these people are wrong about their own experiences all of the time becomes more and more unlikely. Not all members will take advantage of the perspective their standpoint can offer them. But collectively, oppressed people can form a perspective that challenges the dominant perspective (Medina 2013, 74). On average, as a group, their past experience puts people who experience racism in a better position to apply the concept of racism to new situations than people who don't experience racism.

It should be noted that this epistemic advantage is restricted in scope in two ways. First, the group is epistemic advantaged only in relation to the oppression they experience. ${ }^{11}$ Second, it seems that members of the group can only reliably pick out situations of oppression focused at them in situations that are to some degree familiar to them. Placed in a foreign and totally different civilization, it will be harder to reliably pick out instances of oppression. Although limited in scope, the epistemic advantage of oppressed groups seems significant.

\footnotetext{
11 Of course, the members of the group can have a broader epistemic advantage because of intersectional identities.
} 
Because of their epistemic perspective, the evidence gathered by the Dutch minority who experience racism is different from the evidence that the majority can gather from their experience and from the scientific study of racism. Their epistemic advantage makes their evidence not only different, but also quite strong. For someone who doesn't experience racism, the testimony of those who have firstpersonal experience of racism ought to be an important source of evidence about whether racism is a significant problem. This is where the problem is located; it's the reliability of this evidence that is contested due to testimonial injustice, which deepens the disagreement.

Thus far I have argued that people who experience racism tend to have an epistemic advantage over people who don't because their experiences form a distinct and important source of evidence.

Identifying instances of racism can sometimes be difficult. Does dressing up as Black Pete indeed perpetuate racist stereotypes? Is it offensive to people of color? Because of their personal experiences of racism and their communication about these experiences within their communities, many people of color possess an extensive fund of knowledge about racism. Because of their personal experiences, they will be more sensitive to new experiences of the same kind as these experiences form the way they perceive the world (Grillo and Wildman 1991: 398). This means that they are in a better position than the dominant group to apply their knowledge in new situations, through inferences from earlier experiences, which is an important way to understand the meaning of a specific event (Essed 2008: 447).

Another objection might be that people of color tend to apply the term 'racism' too broadly: 'These days, everything is racist!' This objection assumes that there is some better, narrower, way to apply the term. It highlights that different groups use different concepts of racism with (slightly) different extensions. Given that there are different conceptions of racism, we could ask 'which concept is the most ameliorative'? This is a normative question.

When is a concept better than another concept? This depends on our purposes (Cappelen forthcoming, 9). A very natural proposal for a general purpose is to make people's lives better. Cappelen (2018) argues that one of the reasons a concept may be in need of amelioration is because of its detrimental moral, political, or social effects. When evaluating different concepts, one could say that the 'most ameliorative' concept is the one that has better moral, political, or social effects. ${ }^{12}$ Examples of such effects could be equality, inclusiveness, or justice.

Marginalized groups (people who experience racism) often use a more inclusive notion and such an inclusive notion often seems the most ameliorative. In that sense we have a good (moral) reason to use the more inclusive concepts over the more the narrow concept.

To sum up what I've argued so far: to learn about whether racism is a significant issue in the Netherlands, the testimony of the people who experience racism ought to be an important source of evidence for people who do not experience racism.

\footnotetext{
${ }^{12}$ However, the ameliorated concept should still be epistemically good: it should represent the world adequately. As Simion (2018) argues, amelioration should be constrained by a requirement that there should be no epistemic loss.
} 
In theory, then, there is a relatively straightforward rational resolution of the debate about racism. The dominant group rationally ought to see the non-dominant group as a trustworthy epistemic party with important evidence on the relevant issue and take seriously what they bring to the table. Members of the dominant group could take the disagreement as good news: an opportunity to learn from others and to revise their beliefs accordingly (Christensen 2007). This way, by trusting that people of color possess important evidence about racism and accepting their testimony, the disagreement could be resolved.

However, in the case of racism in the Netherlands and Black Pete-as well as in many others - this is not what happens. It's plausible that this is because of racial bias.

Judgments about whether someone is a credible testifier are made very quickly and are based on appearances. Especially, we make social judgment about people based on their faces (Hugenberg and Wilson 2013) and we do this after being exposed to them for less than a second (Todorov et al. 2009). Someone's implicit race biases are a strong predictor of their evaluations of trustworthiness: a person with implicit race biases will have less social trust in a person of another race (Stanley et al. 2011). These implicit racial biases are not rare; they occur widely. Research suggests that white perceivers often make negative social judgements about people with Afrocentric features and/or darker skin tones based on their facial appearances (Hugenberg and Wilson 2013: 171-173). So, people of color are often judged to be less trustworthy by white perceivers. It seems likely that this extends to judgments about the trustworthiness of their testimony.

All this seems to support the claim that the testimony of people of color on racism is often not given the appropriate credibility due to racial prejudice, as is suggested by a.o. Mills (2007). Only some of the people who do not experience racism take first-personal testimony about racism to be a weighty source of evidence.

We can now see how testimonial injustice causes injustice-based deep disagreement on racism. As noted in Sect. 2 above, a disagreement is deep when it involves disagreement about relatively fundamental epistemic principles. This is exactly the effect of testimonial injustice: it adds to the original disagreement a higher-order disagreement about epistemic principles governing the evaluation and uptake of testimony. In addition to the original disagreement about whether racism is a significant problem, there is now a further disagreement about whose testimony counts as good of evidence to settle this question or about how testimony by victims of racism ought to be weighed against other sources of evidence. More specifically: the majority who don't experience racism themselves implicitly or explicitly reject an epistemic principle that stipulates how testimony ought to be treated-or, even more precisely, they reject the application of this principle to the case at handwhereas the minority who does experience racism firsthand takes (this application of) such a principle to be correct.

Following Lynch (2016), deep disagreements can concern (a) conflicting epistemic principles or (b) a different ordering of the same epistemic principles. The deep disagreement on racism also takes these two forms. Some people might not take the testimony of people of color seriously at all and reject any principle to 
the effect that testimony about firsthand experiences of racism ought to be given significant weight. In that case, there are conflicting epistemic principles at play. Their evidence might only consist of their own experiences (and the experience of people like them). As they do not experience racism themselves and are not aware of it happening, they might conclude that racism is not a significant issue. Other people might include testimony of people of color in their body of evidence, but might fail to give it the appropriate weight, for instance by failing to treat it as important testimony. That is a case of a different ordering of epistemic principles. They might give the testimony of those who experience racism some weight, but because they themselves do not experience racism and because they do not give enough weight to the testimony of those who do, they might still conclude that racism is not a significant issue. In both cases, testimonial injustice causes the disagreement on racism to become deep. The result is a lack of evidence for the significance of racism, from the point of view of the dominant group. ${ }^{13}$

One might object to this by denying that the relevant epistemic principles are 'relatively basic'. After all, the characterization of deep disagreement given above requires the disagreement to be about relatively basic epistemic principles. In response, note that it is hard to provide clear and objective general criteria for when principles are 'relatively basic'. But one strong reason to think that the principles at stake in the present case ought to count as relatively basic is that it's difficult to see how someone who is doubtful of the probative value of testimony about firsthand experiences of racism could be convinced otherwise without relying on claims about features of such testimony. That is, it's difficult to see how one could give a noncircular argument for the principles at stake. Firsthand experience is, by definition, (partially) inaccessible to others. Someone who doesn't think firsthand experience is a privileged and private source of evidence will not be convinced when you point out that undergoing racism or other forms of oppression is different from merely observing it or learning about it through systematic scientific research, precisely because this latter point already assumes that there is something epistemically unique and important about firsthand experience.

I conclude that testimonial injustice can be a cause of disagreements about racism that become deep. Let's turn to how hermeneutical injustice can deepen disagreement next.

\section{Hermeneutical injustice and deep disagreement}

Hermeneutical injustice, too, can play a role in deepening disagreement. After a short detour through standpoint theory, I show how hermeneutical injustice can cause injustice-based deep disagreement on racism.

Pohlhaus (2012) argues that epistemic agents are both situated and interdependent. Your situation or social position determines what you are likely to notice and what you pay attention to (as was also noted in the previous section). Epistemic

13 This resembles white ignorance as described by Mills (2007). 
agents are also interdependent. This means that epistemic resources (or conceptual skills) are shared by groups, which means agents depend on others to develop resources that match their experiences.

Epistemic resources can be described as conceptual skills or conceptual know how; for example the skill to employ the concept 'sexual harassment' correctly in different situations (Elzinga 2018). Someone who is familiar with the concept of sexual harassment and also knows how to apply it correctly will be able to recognize instances of sexual harassment and make sense of such events. This way, Elzinga argues, an epistemic resource can be used to make sense of certain experiences and enables a specific epistemic perspective on the world.

As Pohlhaus (2012) describes, when such epistemic resources are formed, a dominant group will tend to have more influence than a non-dominant group. They will have a stronger influence on which epistemic resources are widely available and used. In this way, epistemic resources that are used to make sense of what goes on in a society come to reflect the way the dominant group sees that society. They describe and make sense of the world largely from the situation or epistemic perspective of the dominant group. The dominant group might believe that their epistemic perspective is universal, not realizing that there are differences in interpretative tools across groups due to differences in epistemic perspectives (Medina 2013). From the point of view of the non-dominant group, however, there may be gaps in the language, concepts, and criteria that are used to describe the world on a societal level (Pohlhaus 2012). An example of this is the epistemic resource of racism, on which I will elaborate below.

With this in mind, I turn to hermeneutical injustice. The form of hermeneutical injustice I am focusing on occurs when a person is hindered in sharing conceptual resources which she herself possesses with people outside her group (Dotson 2012: 32; Fricker 2013: 1319; 2016: 166-167 ; Medina 2017: 43-44).

When a non-dominant group develops resources that are important for them to describe their experiences, but there is no uptake of these resources by dominantly situated groups, a member of this non-dominant group is hindered in making herself understood by members of those dominant groups. This is an epistemic injustice, as individuals are unjustly hindered in sharing their knowledge.

Ignorance of concepts employed by marginally situated knowers need not be intentional and might be overcome. However, if members of a dominant group continue to refuse to do something about their ignorance when confronted by itwhen they refuse to learn the conceptual resources they missed out on-the result is willful hermeneutical ignorance (Pohlhaus 2012).

How is hermeneutical injustice related to the debate on racism? The conceptual resources required for describing and making sense of racism (the skill to use the relevant concepts) are very well developed, especially in communities that experience racism. A very general example is the aforementioned conceptualization of racism as 'everyday racism'. Another example is the concept of 'institutional racism', which refers to racist practices of social and political institutions, like in healthcare policies or housing policies. Concepts like these are used to describe and recognize instances of racism and to make sense of them. They enable a perspective 
on the world in which racism is salient and can be described, discussed, and analyzed.

In the Netherlands, too, concepts describing racism are well established within certain minority communities. The concept 'everyday racism', introduced by Essed (1991), has been used for decades. On a communal level and in public discourse, however, the occurrence of racism is often denied in the Netherlands (Ghorashi 2014: 103). Often, the suggestion that racism is a problem in the Netherlands is met with a strong dismissive attitude or with utter silence. Using the word 'racism' is often seen as a way that migrants try to silence their opponents (Ghorashi 2014: 113).

Hence, there is a lack of uptake in society at large of the rich epistemic resources available to describe 'racism'. This is a case of hermeneutical injustice.

Not having or using a conceptual resource should be differentiated from both disagreeing without lacking the appropriate concepts and being wrong in applying a conceptual resource. Note that the mere denial of racism in a certain situation is no hermeneutical injustice it itself. Someone who denies the significance of racism in the Netherlands, while being aware of, and using, the relevant concepts of racism, just disagrees with people who think racism is a significant problem. Similarly, someone who denies that Black Pete is an instance of racism, while responding to the relevant evidence and available concepts, disagrees with those who think it is racism. But disagreeing alone not lead to the committing of a hermeneutical injustice. Also, you can be wrong without lacking the appropriate concepts by failing to apply a conceptual resource.

Hermeneutical injustice comes into play when there is no uptake of relevant concepts developed by an oppressed group. That there is often no uptake of the conceptual resources relevant to racism becomes clear when one considers that, in spite of minor shifts in recent years, racism is barely addressed in the Netherlands. There even seems to be an unwillingness to use the term 'racism' (Witte 2010: 17). According to Wekker (2016: 153-154), this is because racism is supposedly not an issue. If people disagree, they are accused of overreacting, being overly sensitive and being unable to take a joke (ibid:32). Because white people don't experience racism, the assumption that the Netherlands is not racist is the dominant way to reflect on Dutch society. As a result of this silence on racism, there is no shared vocabulary to talk about racism in the Netherlands. There is, from the dominant point of view, no need for elaborate conceptual resources to describe and make sense of experiences of racism. ${ }^{14}$

For example, concepts like 'white privilege', 'white fragility', 'black facing' or 'systematic racism' are not as widely known and used as they are in, for example, the United States, although there is a growing attention to these and similar concepts. It could be that these concepts are not widely used because they do not fit well within the Dutch context and history. If this were the case, you would expect other concepts to take their place. However, I am not aware of any concepts

\footnotetext{
14 I'm overgeneralizing here to keep it simple. There are many positions in this debate and not all white Dutch people think the same way and not all Dutch non-white people think the same way.
} 
concerning racism that are used on a broad societal level to address racism in a constructive way.

As a result, the group that is the object of racism is severely limited in their ability to discuss racism constructively for at least a couple of reasons. First, there are no, or very little, shared epistemic resources because of the different social experiences of the two groups. Second, people who experience racism have trouble fruitfully discussing their experiences with people outside their group because of (willfull) hermeneutical ignorance. As Hondius (2014: 274) writes: 'What is not explicitly mentioned is hard to challenge.' This lack of discussion about racism further reinforces the false belief on the part of the dominant group that racism is not an issue in the Netherlands.

In short, epistemic resources are developed and shared to reflect the experiences of communities, but when there is oppression, some communities might be epistemically left out of the process of developing or sharing these resources. They might form their own resources, reflecting their experiences, but they are not shared on a communal level. The result is a lack of shared vocabulary.

This lack, in turn, might strengthen the idea that first-personal testimony on racism is unreliable. As was discussed in the previous section, a member of a dominant group might judge someone who testifies on racism as unreliable because of identity-prejudices (testimonial injustice). But another reason to judge someone as unreliable is when their testimony does not make sense to you, which may be caused by a lack of shared concepts (hermeneutic injustice). For example, if a testifier asserts 'Black Pete is racist', when you take yourself to know that Black Pete is just part of an innocent tradition, this doesn't make sense. So why listen?

We can now see how hermeneutical injustice deepens disagreement. A lack of shared concepts to talk about racism leads to higher-order disagreement about what counts as credible and trustworthy testimony. The dominant group will live by the generally sensible epistemic principle that they judge testimony that is couched in concepts and terms that they don't understand as unreliable. But the higher-order disagreement that arises concerns the application of that principle to the case at hand. While the dominant group will see this case as a straightforward instance of testimony that makes little sense, the non-dominant group will see this application as unjustified, because the dominant epistemic agents ought to know better, or at least make an effort to educate themselves, rather than dismiss the testimony of nondominant groups out of hand.

The disagreement is deepened further because there is a negative feedback loop between testimonial and hermeneutical injustice. Ideally, the dominant group might incorporate epistemic resources of the non-dominant group by listening to what this latter group has to say. But then testimonial injustice comes into play because an important way to learn about the relevant epistemic resources is by accepting testimony of people who experience racism. Testimonial injustice hinders this process and reduces the chance that shared resources will develop. This way, testimonial injustice reinforces hermeneutical injustice. Hermeneutical injustice can in turn also reinforce testimonial injustice. When words, concepts, or criteria do not match the experience of the dominant epistemic agents (hermeneutical injustice), it's easy for them to dismiss the non-dominant testimony (testimonial injustice) and 
conclude that members of the non-dominant group are overreacting: a tempest in a teapot. So while both kinds of epistemic injustice can deepen disagreements on their own, they can also reinforce each other, deepening the disagreement even more and making it even harder to resolve.

\section{Conclusion: from epistemic injustice to deep disagreement}

I have argued that epistemic injustice can deepen disagreement. The debate on racism in the Netherlands shows how. Without epistemic injustice, the original disagreement on whether racism is a significant issue in the Netherlands, could probably be easily resolved by considering the relevant evidence. This is not at all what happens, however. Because of pre-existing epistemic injustice, the original disagreement is compounded with higher-order disagreements about what counts as evidence.

Specifically, there is disagreement about (the application of) epistemic principles concerning (A) whether private first-personal experience of racism is a weighty source of evidence in this domain, (B) whether victims of racism count as important testifiers in this domain, and (C) how to assess testimony that is not (fully) intelligible to you because it employs concepts and terminology you are unfamiliar with. The dominant group can easily deny that there is anything new or relevant to be known about racism in the Netherlands by dismissing the relevant testimony and epistemic resources, which boils down to disagreement on the level of epistemic principles concerning (A), (B), and (C).

Because of epistemic injustice, it is hard to argue for or against the validity of epistemic principles concerning (A), (B), and (C) in a dispute-independent way. The epistemic injustices at work make it difficult or impossible to exchange epistemic reasons that are accepted by both parties, which shows that the relevant principles are indeed of the relatively fundamental sort required for disagreements to count as deep. This means the disagreement becomes very difficult to resolve. Non-dominant epistemic agents lack the perceived credibility and tools to convince dominant agents of the existence and nature of their experiences.

This kind of 'injustice-based' deep disagreement differs from the kinds of deep disagreements that the literature has focused on. In cases like Young Earth Creationist, it's a difference in worldviews that leads to deep disagreement. Here, however, epistemic injustice deepens a disagreement that would otherwise have been a regular disagreement. The disagreement is only deep because of epistemic injustice.

Although I have focused on the case of racism and Black Pete as a case study in this paper, I want to suggest that disagreements like these, which become deep due to epistemic injustice, can and do occur more widely. This discussion might be useful to look at other cases involving racism, like disagreement about the Black Lives Matter movement. But it might also be used as a lens to look at disagreements involving different kinds of epistemic oppression. When a disagreement appears to have become deep and involves a group that is on the receiving end of epistemic injustices, it might be a case of injustice-based deep disagreement. Think of 
disagreements where the testimony of women, disabled people, old people, and chronically ill people about their own experiences is contested. Attention to the details of such disagreements and empirical research on them could show whether these disagreements are indeed deepened by epistemic injustices. Identifying such cases will be relevant in so far as rationality and morality might require different responses to them than to ordinary disagreements and 'classic' deep disagreements. Hence, understanding injustice-based deep disagreements seems to me to be a project not only of theoretical interest, but also of great practical and social relevance.

Acknowledgements Anonymous reviewers, Jeroen de Ridder, Chris Ranalli, Raymil Helstone, Rik Peels, René van Woudenberg, Catarina Dutilh Novaes, Jan-Willem Wieland, Mikkel Gerken, Christoph Jaeger, Jennifer Lackey, Klemens Kappel, Tamarinde Haven, Wout Bisschop, Gijsbert van der Brink, Michael Hannon and audiences at a.o. the Summer School in Social Epistemology (University of Copenhagen), 7th WFAP Graduate Conference \& OZSW conference 2018.

Open Access This article is licensed under a Creative Commons Attribution 4.0 International License, which permits use, sharing, adaptation, distribution and reproduction in any medium or format, as long as you give appropriate credit to the original author(s) and the source, provide a link to the Creative Commons licence, and indicate if changes were made. The images or other third party material in this article are included in the article's Creative Commons licence, unless indicated otherwise in a credit line to the material. If material is not included in the article's Creative Commons licence and your intended use is not permitted by statutory regulation or exceeds the permitted use, you will need to obtain permission directly from the copyright holder. To view a copy of this licence, visit http:// creativecommons.org/licenses/by/4.0/.

\section{References}

Aikin, S. F. (2018). Dialecticality and deep disagreement. Symposion: Theoretical and Applied Inquiries in Philosophy and Social Sciences, 5(2), 173-179.

Aikin, S. F. (2019). Deep disagreement, the dark enlightenment, and the rhetoric of the red pill. Journal of Applied Philosophy, 36(3), 420-435.

Alston, W. P. (1986). Epistemic circularity. Philosophy and Phenomenological Research, 47(1), 1-30.

Berenstain, N. (2016). Epistemic exploitation. Ergo, an Open Access Journal of Philosophy, 3.

Cappelen, H. (2018). Fixing language: An essay on conceptual engineering. Oxford: Oxford University Press.

Cappelen, H. (forthcoming). Conceptual engineering: The master argument. In H. Cappelen, D. Plunkett \& A. Burgess (Eds.), Conceptual Engineering and Conceptual Ethics. Oxford: Oxford University Press.

Christensen, D. (2007). Epistemology of disagreement: The good news. Philosophical Review, 116(2), $187-217$.

Coady, D. (2017). Epistemic injustice as distributive injustice. In I. J. Kidd, J. Medina, \& G. Pohlhaus Jr. (Eds.), The Routledge handbook of epistemic injustice (pp. 61-68). New York: Routledge.

Dormandy, K. (2018). Disagreement from the religious margins. Res Philosophica, 95(3), 371-395.

Dotson, K. (2012). A cautionary tale: On limiting epistemic oppression. Frontiers, 33(1), $24-47$.

Duran, C. (2016). Levels of depth in deep disagreement. In Argumentation, objectivity, and bias: Proceedings of the 11th conference of the Ontario Society for the Study of Argumentation. OSSA 11 Paper Archive, Paper 109.

Dutilh Novaes, C., Sullivan, E., Lagewaard, T. J., \& Alfano, M. (2020). Van mening veranderen op Twitter? Zwarte Piet als casus. In J. de Ridder, R. Vliegenthart \& J. Zuure (Eds.), Doen, Durven of de Waarheid? (pp. 219-238). Amsterdam: Amsterdam University Press. 
Elzinga, B. (2018). Hermeneutical injustice and liberatory education. The Southern Journal of Philosophy, 56(1), 59-82.

Essed, P. (2008). Everyday racism. In J. Hartwell Moore (Ed.), Encyclopedia of race and racism (pp. 447-449). Farmington Hills: Thomson Gale.

Essed, P. (2018). Alledaags Racisme (revised ed.). Amsterdam: Feministische Uitgeverij Sara.

Feldman, R. (2005). Deep disagreement, rational resolutions, and critical thinking. Informal Logic, 25(1), $12-23$.

Feldman, R. (2006). Epistemological puzzles about disagreement. In S. Hetherington (Ed.), Epistemology futures (pp. 216-236). Oxford: Oxford University Press.

Fogelin, R. (1985). The logic of deep disagreements. Informal Logic, 7(1), 1-8.

Fricker, E. (1995). Critical notice: Telling and trusting-Reductionism and anti-reductionism in the epistemology of testimony. Mind, 104(414), 393-411.

Fricker, M. (2007). Epistemic Injustice: Power and the Ethics of Knowing. Oxford: Oxford University Press.

Fricker, M. (2013). Epistemic justice as a condition of political freedom? Synthese, 190(7), 1317-1332.

Fricker, M. (2016). Epistemic Injustice and the Preservation of Ignorance. In R. Peels \& M. Blaauw (Eds.), The epistemic dimensions of ignorance (pp. 160-177). Cambridge: Cambridge University Press.

Fricker, M. (2017). Evolving concepts of epistemic injustice. In Kidd, I. J., Medina, J., \& Pohlhaus Jr, G. (Eds.), Routledge handbook of epistemic injustice. Routledge handbooks in philosophy. Routledge, pp. 53-60. ISBN 9781138828254.

Gerken, M. (2019). Pragmatic encroachment and the challenge from epistemic injustice. Philosophers' Imprint, 19(15), 1-19.

Ghorashi, H. (2014). Racism and the 'Ungrateful Other' in the Netherlands. In P. Essed \& I. Hoving (Eds.), Dutch racism (pp. 101-117). Amsterdam: Rodopi.

Grillo, T., \& Wildman, S. M. (1991). Obscuring the importance of race: The implication of making comparisons between racism and sexism (or other-isms). Duke Law Journal, 1991(2), 397-412.

Harding, S. (1993). Rethinking standpoint epistemology: what is strong objectivity? In L. Alcoff \& E. Potter (Eds.), Feminist epistemologies (pp. 437-470). New York: Routledge.

Hilhorst, S., \& Hermes, J. (2016). 'We have given up so much': Passion and denial in the Dutch Zwarte Piet (Black Pete) controversy. European Journal of Cultural Studies, 19(3), 218-233.

Hondius, D. G. (2014). Black dutch voices: Reports from a country that leaves racism unchallenged. In P. Essed \& I. Hoving (Eds.), Dutch racism (pp. 273-293). Amsterdam: Rodopi.

Hugenberg, K., \& Wilson, J. P. (2013). Faces are Central to Social Cognition. In D. E. Carlston (Ed.), Oxford library of psychology. The Oxford Handbook of social cognition (pp. 167-193). New York: Oxford University Press.

Huijnk, W. \& Gijsberts, M. \& Dagevos, J. (2014) Jaarrapport integratie 2013. Den Haag: Sociaal en Cultureel Planbureau. Retrieved from https://www.scp.nl/Publicaties/Alle_publicaties/Publicaties_ 2014/Jaarrapport_integratie_2013.

Kappel, K. (2012). The problem of deep disagreement. Discipline Filosofiche, 22(2), 7-25.

Kappel, K. (2018). Higher order evidence and deep disagreement. Topoi, 1-12.

Kelly, T. (2005). The epistemic significance of disagreement. In J. Hawthorne (Ed.), Oxford studies in epistemology 1 (pp. 167-197). Oxford: Oxford University Press.

Van Vliet L. \& Kester, J. (2018). Onderzoek: Uiterlijk van Zwarte Piet. Opiniepeiling Rapport Eenvandaag. Retrieved from: https://eenvandaag.avrotros.nl/fileadmin/user_upload/PDF/ Rapportage_zwarte_piet_def.pdf.

Kidd, I. J., Medina, J., \& Pohlhaus, G., Jr. (2017). The Routledge handbook of epistemic injustice. New York: Routledge.

Lackey, J. (2008). Learning from words: Testimony as a source of knowledge. Oxford: Oxford University Press.

Lackey, J. (2018). Credibility and the distribution of epistemic goods. In Mc Cain Kevin (Ed.), Believing in accordance with the evidence (pp. 145-168). New York: Springer.

Lynch, M. P. (2010). Epistemic circularity and epistemic incommensurability. In A. Haddock, A. Miller, \& D. Pritchard (Eds.), Social epistemology (pp. 262-277). Oxford: Oxford University Press.

Lynch, Michael P. (2016). After the spade turns: Disagreement, first principles and epistemic contractarianism. International Journal for the Study of Skepticism, 6(2-3), 248-259.

Matheson, J. (2018). Deep disagreements and rational resolution. Topoi 1-13. https://doi.org/10.1007/ s11245-018-9576-y 
McKinnon, R. (2016). Epistemic injustice. Philosophy Compass, 11(8), 437-446.

Medina, J. (2013). The epistemology of resistance: Gender and racial oppression, epistemic injustice, and the social imagination. Oxford: Oxford University Press.

Medina, J. (2016). Ignorance and racial insensitivity. In R. Peels \& M. Blaauw (Eds.), The epistemic dimensions of ignorance (pp. 178-201). Cambridge: Cambridge University Press.

Medina, J. (2017). Varieties of hermeneutical injustice. In I. J. Kidd, J. Medina, \& G. Pohlhaus Jr. (Eds.), The Routledge handbook of epistemic injustice (pp. 41-52). New York: Routledge.

Memedi, V. (2007). Resolving deep disagreement: a case in point. In H. V. Hansen, C. W. Tindale, R. H. Johnson, \& J. A. Blair (Eds.), Dissensus and the search for common ground. Windsor: OSSA Conference Archive.

Mills, C. (2007). White ignorance. In S. Sullivan \& N. Tuana (Eds.), Race and epistemologies of ignorance (pp. 11-38). New York: State University of New York Press.

Narayan, U. (2004). The project of feminist epistemology: Perspectives from a nonwestern feminist. In S. G. Harding (Ed.), The feminist standpoint theory reader: Intellectual and political controversies (pp. 213-224). New York: Routledge.

Plunkett, D., \& Sundell, T. (2013). Disagreement and the semantics of normative and evaluative terms. Philosophers' Imprint, 13(23), 1-37.

Pohlhaus, G. (2012). Relational knowing and epistemic injustice: Toward a theory of willful hermeneutical ignorance. Hypatia, 27(4), 715-735.

Ranalli, (2018). What is deep disagreement? Topoi. https://doi.org/10.1007/s11245-018-9600-2.

Rasit, E. \& Tielbeke, J. (2018, March 28). Rachid is ook gewoon een nette jongen. Retrieved from: https://www.groene.nl/artikel/rachid-is-ook-gewoon-een-nette-jongen.

Rodenberg, J., \& Wagenaar, P. (2016). Essentializing 'Black Pete': competing narratives surrounding the Sinterklaas tradition in the Netherlands. International Journal of Heritage Studies, 22(9), 716-728.

Simion, M. (2018). The 'should' in conceptual engineering. Inquiry, 61(8), 914-928.

Stanley, D. A., Sokol-Hessner, P., Banaji, M. R., \& Phelps, E. A. (2011). Implicit race attitudes predict trustworthiness judgments and economic trustdecisions. Proceedings of the National Academy of Sciences, 108(19), 7710-7715.

Stroud, S. (2019). Conceptual disagreement. American Philosophical Quarterly, 56(1), 15-28.

Todorov, A., Pakrashi, M., \& Oosterhof, N. N. (2009). Evaluating faces on trustworthiness after minimal time exposure. Social Cognition, 27, 813-833.

Van den Berg, C., Blommaert, L., Bijleveld, C., \& Ruiter, S. (2017). Veroordeeld tot (g)een baan: hoe delict- en persoonlijkheidskenmerken arbeidsmarktkansen voor veroordeelden beïnvloeden. Tijdschrift voor Criminologie, 59(1-2), 113-135.

Wekker, G. (2016). White innocence. Paradoxes of colonialism and race. Durham: Duke University Press.

Witte, R. (2010). Al eeuwenlang een gastvrij volk. Racistisch geweld en overheidsreacties (1950-2009). Amsterdam: Askant.

Publisher's Note Springer Nature remains neutral with regard to jurisdictional claims in published maps and institutional affiliations. 